\title{
Expanded endonasal endoscopic resection of anterior fossa meningiomas: report of 13 cases and meta-analysis of the literature
}

\author{
Jamie J. Van Gompel, M.D., ${ }^{1}$ Giorgio Frank, M.D., ${ }^{2}$ Ernesto Pasquini, M.D., 2 \\ Matteo Zoli, M.D., ${ }^{2}$ Jason Hoover, M.D., ${ }^{1}$ ANd GiUseppe Lanzino, M.D. ${ }^{1}$ \\ ${ }^{1}$ Department of Neurological Surgery, Mayo Clinic, Rochester, Minnesota; and ${ }^{2}$ Center of Surgery for \\ Pituitary Tumors and Endoscopic Skull Base Surgery, Bellaria Hospital, Bologna, Italy
}

\begin{abstract}
Object. Transnasal endoscopic (TNE) approaches have been proposed for the resection of anterior cranial base meningiomas. The purpose of this article was to evaluate the results of endoscopic resection of anterior cranial fossa meningiomas by reviewing available published data in addition to the authors' experience with 13 cases.

Methods. The literature was searched via OVID to identify all available disaggregate data pertaining to anterior fossa meningiomas treated primarily by TNE. In addition, the authors reviewed the records of a personal series of 13 patients who underwent TNE removal of parasellar meningiomas through a pure TNE approach.

Results. Meta-analysis from studies included a total of 69 patients with adequate disaggregated data to summarize. Mean age ( \pm SD) at surgery was $53.3 \pm 13.0$ years (range $27-80$ years); $78 \%$ of the patients were women. Tumor size was skewed toward smaller lesions, with a mean volume of $24.4 \pm 2.9 \mathrm{~cm}^{3}$. Intraoperative impressions were of gross-total resection in $76 \%$ of cases. The most common complication reported was CSF leakage, occurring in $32 \%$ of the cases (22 of 69). The rate of CSF leakage was not affected by size $(\mathrm{p}=0.52)$, location of tumor $(\mathrm{p}=0.9)$, or age $(\mathrm{p}=0.56)$. There was 1 death overall. The mean duration of follow-up was $21 \pm 18$ months.

Conclusions. Transnasal endoscopic resection of anterior cranial base meningiomas is feasible in selected cases. Reported resection rates are adequate, although the follow-up in the reported series is too short (mean 21 months) to make definitive conclusions regarding the long-term effectiveness. Cerebrospinal fluid leakage is a common complication, although it appears not to be associated with additional morbidity except for the need for reoperation. Long-term results are necessary before considering TNE resection as a valid alternative, in selected cases, to the more established transcranial techniques. (DOI: 10.3171/2011.1.FOCUS118)
\end{abstract}

\section{KEY WORDS • meningioma • endoscopic approach • endonasal approach • neurosurgery}

$\mathrm{M}$ IDLINE anterior fossa meningiomas, such as olfactory groove and parasellar (including both tuberculum sellae and planum sphenoidale) tumors constitute approximately $12 \%-20 \%$ of all intracranial meningiomas. ${ }^{23}$ Treatment for anterior fossa meningiomas typically entails resection. Standard transcranial surgery includes unilateral frontotemporal, or subfrontal and bifrontal approaches. ${ }^{23}$ Newer approaches include minimally invasive supraorbital keyhole craniotomies with endoscopic assistance. ${ }^{9,10}$

In the past 10 years, there has been an explosion of interest in the application of TNE therapy for sellar and anterior cranial fossa lesions. With increased experience, surgeons have tackled more formidable pathologies such as larger and more technically difficult anterior fossa meningiomas. ${ }^{2}$ Advantages of TNE over transcranial approaches include minimization of brain retraction and optic apparatus manipulation, earlier identification of the pituitary gland, and a cosmetically appealing postopera-

Abbreviation used in this paper: $\mathrm{TNE}=$ transnasal endoscopic. tive result with no visible scar. Endoscopic transnasal surgery is also appealing to patients because it is perceived as being less invasive than the more traditional transcranial route. ${ }^{25}$ However, despite several small single-center series, the potential role of TNE resection for anterior cranial base meningiomas is not defined, and to date there has been no critical evaluation of the literature regarding its effectiveness. In this report, we systematically analyze the available literature regarding TNE surgery for anterior skull base meningiomas. We also include a personal series of patients surgically treated by 2 of the authors (G.F. and E.P.).

\section{Methods}

\section{Chart Review}

The records of 13 consecutive patients who underwent TNE removal of parasellar meningiomas through a pure TNE approach performed by 2 of the authors (G.F. and E.P.) were retrospectively reviewed. Standard extended 
endoscopic transtuberculum approaches were performed (Video 1).

Video 1. Case 2. An edited recording of the removal of a parasellar meningioma, demonstrating representative portions of the approach and resection and, at the end of the video clip, the closure with fascia lata. Click here to view with Windows Media Player. Click here to view with Quicktime.

\section{Literature Search}

Unique articles were identified by means of Ovid MEDLINE using the following MeSH headings: "endonasal," "endoscopic," "extended transphenoidal," "meningioma," "sellar," "transnasal," "olfactory groove," "tuberculum sellae," "planum," alone and in combination. We then searched all references in these manuscripts. The inclusion criteria for this set of articles were as follows: 1) individual patient data were reported in a disaggregated fashion, 2) the primary treatment modality was clearly reported and limited to endonasal endoscopic surgery, and 3) outcome data were reported, including follow-up duration and/or time until death.

\section{Data Extraction}

Data from individual reports and case series were extracted. Manuscripts reporting only sum-aggregate results were not used, as these data did not permit meaningful analysis; however, these articles are included in our discussion. Tumors with posterior fossa extension were excluded due to unknown origin; this applied to the case series reported by Gardner et al., ${ }^{14}$ from which 7 tumors were excluded as being possibly petroclival. Follow-up duration was tabulated in months. Disease status, mortality, and cause of death were extracted and coded for as of death or the termination of follow-up. There was inadequate follow-up to permit survival analysis. We did not distinguish between tuberculum sellae and planum sphenoidale tumors, we simply included this as one group, labeled PS (parasellar). This was done because the difference between these two locations was often not clearly defined in the original manuscripts, and also the largest series on this topic did not distinguish these tumors, recognizing the difficulty in separating them. ${ }^{14}$

\section{Statistical Analysis}

The Pearson chi-square test was used to analyze for differences in preoperative categorical factors. The results of statistical tests were considered significant at $\mathrm{p}$ $<0.05$. Continuous variables are presented with the SE unless otherwise noted. Differences in age were tested for significance using the independent-sample t-test after demonstrating normality of the data. All descriptive and statistical analysis was performed using JMP 8.0.

\section{Results}

\section{Patient Series}

Thirteen patients were treated by 2 of the authors (G.F. and E.P.) for meningioma using a TNE approach between 2003 and 2010. There were 11 women and 2 men with a mean age of $62 \pm 15$ years (range 31-77 years, median 67 years). Two patients (15\%) had undergone prior resection via a craniotomy. The maximum diameter of tumors ranged from 13 to $35 \mathrm{~mm}$, with an average of 24.3 $\pm 6.6 \mathrm{~mm}$. Figure 1 shows the lesions in the first 8 consecutive cases as examples of the spectrum of pathology treated. Twelve of the 13 patients presented with visual deficit and 1 had persistent headaches (Table 1). At surgery, tumors were judged to be soft in 3 cases, firm in 5, fibrotic in 3 , and calcified in 2 . Of the 12 patients with documented postoperative visual examinations, vision was found to have improved in 8 , remained unchanged in 4 , and worsened in none. Postoperative imaging confirmed complete tumor resection in 7 of 13 cases; in 6 cases there were small remnants. In these last 6 cases, 3 patients had undergone TNE resection with the only goal being decompression of the optic apparatus. Therefore, of the 10 cases in which radical resection was the goal, it was achieved in 7. Figure 2 demonstrates a typical postoperative appearance after TNE resection. Significant postoperative complications occurred in 1 patient, who suffered a postoperative left anterior cerebral artery stroke causing right leg weakness. There were no episodes of postoperative CSF leakage in this series. Follow-up data were available in 10 patients (mean duration of follow-up 13 months, median 8 months). All but 1 of these 10 patients were alive at the time of this writing (December 2010); in the single patient who died, the cause of death was not related to the tumor or the surgery.

\section{Meta-Analysis}

On the basis of the literature search, we identified a total of 69 patients with adequate disaggregated data to summarize. There were 50 parasellar and 19 olfactory groove tumors. ${ }^{3,5,6,10,14,18,24}$ Patient age was parametrically distributed with a mean $( \pm \mathrm{SD})$ of $53.3 \pm 13.0$ years (range 27-80 years) at the time of surgery. There were 50 women (78\%) and 14 men (21\%). Tumor size was significantly skewed toward smaller lesions with minimum, first quartile, median, third quartile, and maximum values of $1.4,8.6,20,26$, and $109 \mathrm{~cm}^{3}$, respectively. Average maximum diameter was $27.5 \mathrm{~mm}$. In $27 \%$ of cases, the patients had prior treatment either by a transsphenoidal or transcranial approach. Of the 69 resections, $76 \%$ were qualified as gross total; there were equal proportions of those declared subtotal (12\%) or near total (12\%). Overall, the CSF leakage rate was $32 \%$ (with CSF leak occurring in 22 of 69 cases). The CSF leakage rates for olfactory groove and parasellar tumors were $26 \%$ (5 of 19) and $34 \%$ (17 of 50), respectively; this difference was not significant $(p=0.9)$. The CSF leakage rate was not affected by tumor size $(\mathrm{p}=0.5)$ or patient age $(\mathrm{p}=0.6)$. There was 1 death overall. The mean $( \pm \mathrm{SD})$ duration of follow-up was $21 \pm$ 18 months.

\section{Discussion}

Midline anterior fossa meningiomas, specifically olfactory groove and parasellar meningiomas, have conventionally been removed via various transcranial subfrontal approaches. In the modern era of microneurosurgery, the first report of extended transnasal removal of a meningi- 

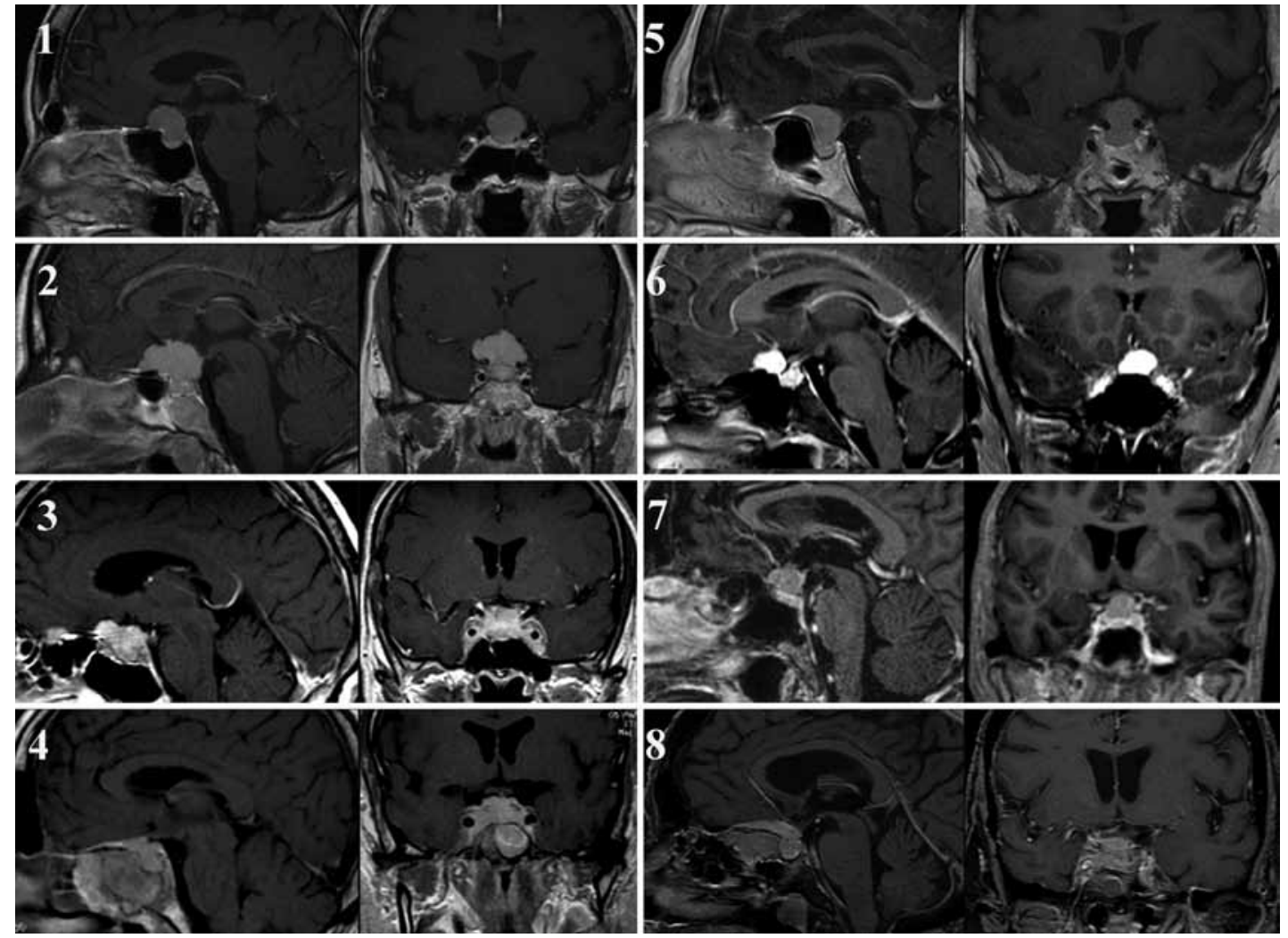

FIG. 1. Preoperative sagittal (left) and coronal (right) contrast-enhanced T1-weighted MR images obtained in the first 8 cases (as numbered) in the senior authors' series of 13, demonstrating typical lesions treated with TNE resection. In general these lesions are midline, do not extend outside the carotid arteries, and are relatively small.

oma is credited to Weiss and coworkers in $1987 .{ }^{3}$ Following the pioneering work of Jho and others, TNE resection has been applied to a variety of lesions of the cranial base including anterior cranial fossa meningiomas. ${ }^{15,16}$ Transnasal endoscopic surgery allows a window to the anterior skull base of the approximately $15-20 \mathrm{~mm}$ left to right by $25-30 \mathrm{~mm}$ anterior to posterior. ${ }^{2}$ The approach is relatively straightforward. However, it has been suggested that resection of complex tumors such as meningiomas through a TNE approach is for the "virtuosos only."11,12

TABLE 1: Clinical and demographic characteristics in 13 patients who underwent TNE resection of parasellar meningiomas*

\begin{tabular}{|c|c|c|c|c|c|c|c|c|}
\hline Case No. & $\begin{array}{c}\text { Age (yrs), } \\
\text { Sex }\end{array}$ & $\begin{array}{c}\text { Tumor } \\
\text { Size }(\mathrm{mm})\end{array}$ & $\begin{array}{l}\text { Previous } \\
\text { Treatment }\end{array}$ & Presenting Symptoms & Postop Vision & Postop MRI & $\mathrm{FU}$ (mos) & Complication \\
\hline 1 & $70, \mathrm{~F}$ & $22 \times 16$ & none & BTHA & normal & negative & 20 & none \\
\hline 2 & $31, \mathrm{~F}$ & $26 \times 18$ & none & BTHA \& rt AD & improved & negative & 11 & none \\
\hline 3 & $59, \mathrm{M}$ & $25 \times 14$ & craniotomy & It blindness \& rt AD & stable & remnant & 65 & none \\
\hline 4 & $68, M$ & $28 \times 27$ & none & rt $A D$ & improved & remnant & 8 & none \\
\hline 5 & $77, \mathrm{~F}$ & $30 \times 25$ & none & It $A D \&$ rt $A D$ & stable & remnant & 3 & stroke† \\
\hline 6 & $32, F$ & $13 \times 10$ & none & headache & normal & negative & 3 & none \\
\hline 7 & $72, \mathrm{~F}$ & $14 \times 12$ & craniotomy & It blindness & improved & remnant & 8 & none \\
\hline 8 & $76, \mathrm{~F}$ & $31 \times 18$ & none & rt blindness \& It AD & stable & remnant & 13 & none \\
\hline 9 & $67, \mathrm{~F}$ & $17 \times 22$ & none & It $A D \&$ rt $A D$ & improved & negative & 3 & none \\
\hline 10 & $69, F$ & $25 \times 12$ & none & BTHA & NA & negative & NA & none \\
\hline 11 & $57, \mathrm{~F}$ & NA & none & BTHA \& AD & improved & negative & NA & none \\
\hline 12 & $64, \mathrm{~F}$ & $20 \times 18$ & none & BTHA & normal & negative & 0 & none \\
\hline 13 & $62, \mathrm{~F}$ & $30 \times 35$ & none & It blindness \& rt AD & stable & remnant & NA & none \\
\hline
\end{tabular}

* $\mathrm{AD}=$ acuity deficit; $\mathrm{BTHA}=$ bitemporal hemianopia; $\mathrm{FU}=$ follow-up; NA = data not available.

$\dagger$ Left anterior cerebral artery ischemia, right lower-extremity hemiparesis. 


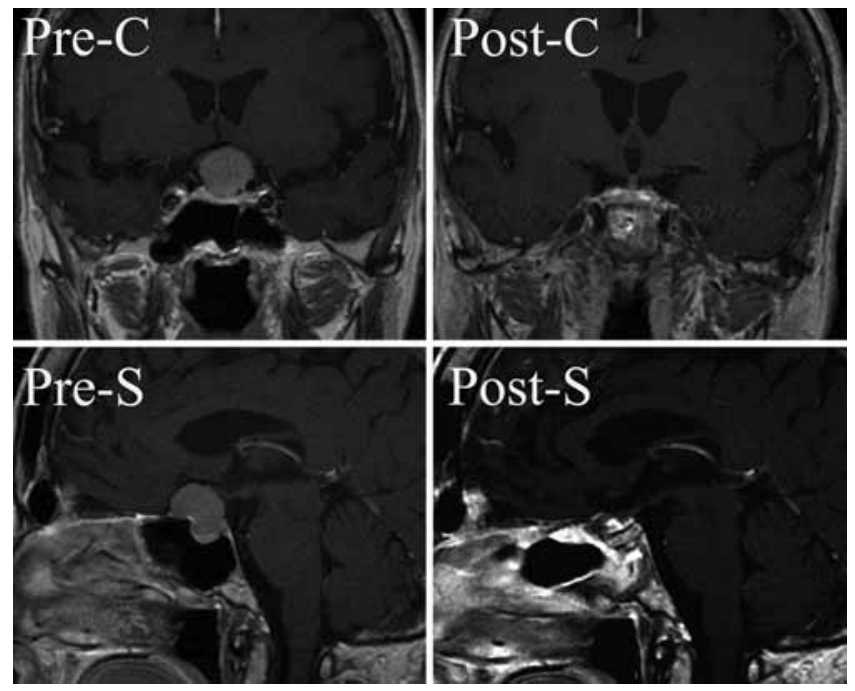

FIG. 2. Case 1. Preoperative (left) and postoperative (right) T1weighted contrast-enhanced coronal (upper) and sagittal (lower) MR images demonstrating a complete resection and the typical postoperative appearance.

We report a meta-analysis of various studies that includes a total of 69 cases of anterior fossa meningiomas treated with TNE therapy and for which enough information was available to allow for a disaggregate analysis. Overall, there were 50 parasellar and 19 olfactory groove meningiomas in addition to the 13 from our series. ${ }^{3,5,6,10,14,24}$ As one would expect, there was a large proportion of women in this series, which is concordant with other large meningioma series. ${ }^{1,13}$ The major shortcoming of evaluating a series of TNE resections of anterior fossa meningiomas at this time is the lack of adequate longterm data. Most currently available reports are relatively limited, as they are series that report the direct surgical accomplishments of the technique and do not focus on appropriate outcome assessment for meningiomas. Most of these studies have 6-24 months of follow-up (mean 21 \pm 18 months). ${ }^{24}$ Therefore, no conclusions can be made about the effectiveness of this surgical strategy.

Direct comparison within one institution between TNE and TC surgery for anterior cranial fossa meningiomas suggested that the amount of resection is similar in the 2 approaches $(86.4 \%$ gross-total resection with TNE treatment and $83.3 \%$ gross-total resection with transcranial surgery). ${ }^{5}$ However, removal is most typically reported as gross total in TNE series and is not gradable in the Simpson grading system, therefore making direct comparison difficult. ${ }^{9,10}$ Overall, the reported gross-total resection rates for TNE surgery are $50 \%-84 \%$, whereas total resection rates vary between $70 \%$ and $100 \%$ with trancranial surgery. ${ }^{3,6,9,10,14,22,24}$ In a series of 51 patients with parasellar meningiomas, de Divitiis et al. ${ }^{5}$ reported that morbidities attributed to transcranial resection, such as hematomas, seizures, and injuries to surrounding neurological structures, were lower in patients treated with a transnasal approach. However, CSF leak was increased with the transnasal approach. A comparison between transcranial and TNE resection is not feasible based on the available data. The major limit of TNE surgery for meningiomas is the lateral extent of the tumor and therefore, surgical series of TNE surgery are skewed toward smaller, midline lesions, while transcranial surgery series encompass the entire variety of these tumors, which often are asymmetrical with significant lateral extension and, especially in cases of the olfactory groove variant, can reach a large size.

Cerebrospinal fluid leaks are common after TNE removal of anterior fossa meningiomas (Table 2). The overall CSF leakage rate for this meta-analysis was $32 \%$ (with leaks occurring in 22 of 69 reported cases). ${ }^{3,5,6,10,14,24}$ Cerebrospinal fluid leaks were reported to occur between $0 \%$ and $40 \%$ of the time in individual experiences. ${ }^{3,24}$ In the only interinstitutional series reported, the rate of CSF leakage after TNE was $14 \%$, whereas for transcranial surgery it was $0 \% .{ }^{9,10}$ Despite advances in reconstruction techniques, postoperative CSF leakage remains a significant complication associated with TNE. However, the rate of morbidities such as meningitis is very low despite the need at times for multiple repeated treatments for a recalcitrant CSF leak. ${ }^{9,10}$ Furthermore, although most papers discuss the drastic reduction in postoperative CSF leaks in these patients using vascularized nasoseptal flaps, such as the Janus flap, there is no case series or report formally supporting this notion. ${ }^{21}$ In the series of 13 patients reported herein, we did not encounter any case of CSF leakage. Important factors to consider to explain the very low incidence in our series are the careful selection of patients (many more patients were treated via the transcranial route during the period of this study by one of the senior authors [G.F.]) and the fact that the senior authors (G.F. and E.P.) embraced the TNE approach for anterior cranial base meningioma "late" in their evolution after many years of experience with a variety of other primary sellar lesions.

Visual improvement is the norm after optic nerve decompressive therapy, which appears to be enhanced by the TNE approach. ${ }^{24}$ Authors laud the TNE approach for early decompression of the optic canal and $270^{\circ}$ release compared with transcranial approaches. ${ }^{4-6}$ Typically, visual improvement is reported in $70 \%-80 \%$ of patients who had deterioration of vision preoperatively, and $7 \%-12 \%$ of patients experience worsening of vision postoperatively. ${ }^{8-10}$ Regarding transcranial approaches for parasellar meningiomas, deterioration of vision has been reported as occurring in $19 \%$ of cases. ${ }^{1}$ Further, Nakamura et al..$^{20}$ evaluated vision outcomes based on the size of parasellar meningiomas and the transcranial approach. They reported that for patients with meningiomas less than $30 \mathrm{~mm}$ in diameter, the rate of visual decline after surgery was $9.7 \%$ versus $16 \%$ in those with meningiomas greater than $30 \mathrm{~mm}$. Overall, there appears to be no difference in reported visual outcomes for transcranial versus TNE procedures..$^{22}$ However, we think that the TNE approach may offer some advantages for resection of small midline (usually pure parasellar tumors) causing early visual deficits. In these cases, management of the portion of the tumor under the ipsilateral optic nerve can be challenging, especially in the setting of marginal preoperative visual function. Management of the optic apparatus may not be as challenging or traumatic from 


\section{Endonasal endoscopic management of meningiomas}

TABLE 2: Summary of reported series of anterior skull base meningiomas series treated via TNE approaches*

\begin{tabular}{lcrrrrr}
\hline \multicolumn{1}{c}{ Authors \& Year } & $\begin{array}{c}\text { Total No. of } \\
\text { Cases }\end{array}$ & OG & PS & Years & No. of Cases w/ CSF Leak (\%) & Mean FU (mos) \\
\hline Fatemi et al., 2009 & 14 & 0 & 14 & $2000-2008$ & $4(29)$ & 27 \\
Wang et al., 2009 & 7 & 0 & 7 & $2002-2007$ & $1(14)$ & 23 \\
Gardner et al., 2008† & 28 & 15 & 13 & $2002-2005$ & $3(43)$ & - \\
de Divitis et al., 2008 & 11 & 4 & 7 & $2004-2007$ & $1(100)$ & - \\
Dehdashti et al., 2009 & 1 & 0 & 1 & - & $1(0)$ & - \\
Cook et al., 2004 & 3 & 0 & 3 & - & $0(0)$ & 14 \\
Laufer et al., 2007 & 5 & 0 & 5 & - & & \\
present series & 13 & 0 & 13 & $2003-2010$ &
\end{tabular}

an "inferior" view/approach like the one provided by the TNE exposure.

As expected, patient selection and the surgeon's degree of comfort with one approach over the other are crucial when determining the best surgical strategy for the resection of anterior fossa meningiomas. Patient age, comorbidities, tumor size, relationship to surrounding neurovascular structures, and lateral extension are also important issues to consider. An additional important factor is the consistency of the meningioma. There is an expanding number of series in the literature in which MR imaging has been used to try and predict whether a meningioma is soft/suckable or firm/fibrous. ${ }^{17,19}$ Determining this consistency might assist the surgeon in preoperative planning, patient counseling, and intraoperative decisionmaking.

\section{Conclusions}

A review of early series and our own experience suggests that TNE resection of anterior cranial fossa meningiomas can be safely achieved in selected cases (usually involving small and midline lesions). Cerebrospinal fluid leakage is a significant complication of this approach although its incidence may be decreasing with more experienced and better closure techniques. Visual outcomes are comparable to those achieved with a transcranial approach. However, there is not adequate information regarding the long-term efficacy of TNE surgery for anterior cranial base meningiomas, given that the mean follow-up of published series is only 21 months. Of course, patient selection and surgeon degree of comfort with one approach over the other are important factors in determining the surgical strategy to follow. However, for small, purely midline meningiomas arising from the posterior portion of the planum and/or the tuberculum, the TNE approach may provide some advantages over classic transcranial techniques especially in regard to management of the tumor/optic apparatus interface.

\section{Disclosure}

The authors report no conflict of interest concerning the mate- rials or methods used in this study or the findings specified in this paper.

Author contributions to the study and manuscript preparation include the following. Conception and design: Van Gompel, Frank, Pasquini, Lanzino. Acquisition of data: all authors. Analysis and interpretation of data: Van Gompel, Frank, Pasquini, Zoli, Lanzino. Drafting the article: all authors. Critically revising the article: all authors. Reviewed final version of the manuscript and approved it for submission: all authors. Statistical analysis: Van Gompel. Administrative/technical/material support: Zoli. Study supervision: Frank, Pasquini, Lanzino.

\section{References}

1. Benjamin V, Russell SM: The microsurgical nuances of resecting tuberculum sellae meningiomas. Neurosurgery 56 (2 Suppl):411-417, 2005

2. Catapano D, Sloffer CA, Frank G, Pasquini E, D’Angelo VA, Lanzino G: Comparison between the microscope and endoscope in the direct endonasal extended transsphenoidal approach: anatomical study. J Neurosurg 104:419-425, 2006

3. Cook SW, Smith Z, Kelly DF: Endonasal transsphenoidal removal of tuberculum sellae meningiomas: technical note. Neurosurgery 55:239-246, 2004

4. de Divitiis E, Cavallo LM, Esposito F, Stella L, Messina A: Extended endoscopic transsphenoidal approach for tuberculum sellae meningiomas. Neurosurgery 61 (5 Suppl 2):229238, 2007

5. de Divitiis E, Esposito F, Cappabianca P, Cavallo LM, de Divitiis $\mathrm{O}$ : Tuberculum sellae meningiomas: high route or low route? A series of 51 consecutive cases. Neurosurgery 62: 556-563, 2008

6. de Divitiis E, Esposito F, Cappabianca P, Cavallo LM, de Divitiis O, Esposito I: Endoscopic transnasal resection of anterior cranial fossa meningiomas. Neurosurg Focus 25(6):E8, 2008

7. Dehdashti AR, Ganna A, Witterick I, Gentili F: Expanded endoscopic endonasal approach for anterior cranial base and suprasellar lesions: indications and limitations. Neurosurgery 64:677-89, 2009

8. Dusick JR, Esposito F, Kelly DF, Cohan P, DeSalles A, Becker DP, et al: The extended direct endonasal transsphenoidal approach for nonadenomatous suprasellar tumors. J Neurosurg 102:832-841, 2005

9. Fatemi N, Dusick JR, de Paiva Neto MA, Kelly DF: The endonasal microscopic approach for pituitary adenomas and other parasellar tumors: a 10-year experience. Neurosurgery 63 (4 Suppl 2):244-256, 2008

10. Fatemi N, Dusick JR, de Paiva Neto MA, Malkasian D, Kelly DF: Endonasal versus supraorbital keyhole removal of cranio- 


\section{J. J. Van Gompel et al.}

pharyngiomas and tuberculum sellae meningiomas. Neurosurgery 64 (5 Suppl 2):269-286, 2009

11. Frank G, Pasquini E: Tuberculum sellae meningioma: the extended transsphenoidal approach-for the virtuoso only? World Neurosurg 73:625-626, 2010

12. Frank G, Pasquini E, Mazzatenta D: Extended transsphenoidal approach. J Neurosurg 95:917-918, 2001

13. Ganna A, Dehdashti AR, Karabatsou K, Gentili F: Frontobasal interhemispheric approach for tuberculum sellae meningiomas; long-term visual outcome. Br J Neurosurg 23:422430, 2009

14. Gardner PA, Kassam AB, Thomas A, Snyderman CH, Carrau RL, Mintz AH, et al: Endoscopic endonasal resection of anterior cranial base meningiomas. Neurosurgery 63:36-54, 2008

15. Jho HD: Endoscopic endonasal approach to the optic nerve: a technical note. Minim Invasive Neurosurg 44:190-193, 2001

16. Jho HD, Alfieri A: Endoscopic glabellar approach to the anterior skull base: a technical note. Minim Invasive Neurosurg 45:185-188, 2002

17. Kashimura H, Inoue $\mathrm{T}$, Ogasawara $\mathrm{K}$, Arai H, Otawara $\mathrm{Y}$, Kanbara Y, et al: Prediction of meningioma consistency using fractional anisotropy value measured by magnetic resonance imaging. J Neurosurg 107:784-787, 2007

18. Laufer I, Anand VK, Schwartz TH: Endoscopic, endonasal extended transsphenoidal, transplanum transtuberculum approach for resection of suprasellar lesions. J Neurosurg 106: 400-406, 2007

19. Maiuri F, Iaconetta G, de Divitiis O, Cirillo S, Di Salle F, De Caro ML: Intracranial meningiomas: correlations between MR imaging and histology. Eur J Radiol 31:69-75, 1999

20. Nakamura M, Roser F, Struck M, Vorkapic P, Samii M: Tu- berculum sellae meningiomas: clinical outcome considering different surgical approaches. Neurosurgery 59:1019-1029, 2006

21. Nyquist GG, Anand VK, Singh A, Schwartz TH: Janus flap: bilateral nasoseptal flaps for anterior skull base reconstruction. Otolaryngol Head Neck Surg 142:327-331, 2010

22. Panigrahi M, Varaprasad G: Transcranial/transnasal approach for nonpituitary sellar lesions. Surg Neurol 72:643-647, 2009

23. Rachinger W, Grau S, Tonn JC: Different microsurgical approaches to meningiomas of the anterior cranial base. Acta Neurochir (Wien) 152:931-939, 2010

24. Wang Q, Lu XJ, Li B, Ji WY, Chen KL: Extended endoscopic endonasal transsphenoidal removal of tuberculum sellae meningiomas: a preliminary report. J Clin Neurosci 16:889-893, 2009

25. Zimmer LA, Theodosopoulos PV: Anterior skull base surgery: open versus endoscopic. Curr Opin Otolaryngol Head Neck Surg 17:75-78, 2009

Manuscript submitted January 13, 2011.

Accepted January 24, 2011.

Supplemental online information:

Video: http://mfile.akamai.com/21490/wmv/digitalwbc.download. akamai.com/21492/wm.digitalsource-na-regional/FOCUS11-8.asx (Media Player)

Video: http://mfile.akamai.com/21488/mov/digitalwbc.download. akamai.com/21492/qt.digitalsource-global/FOCUS 11-8.mov (Quicktime)

Address correspondence to: Jamie J. Van Gompel, M.D., Department of Neurologic Surgery, Mayo Clinic, 200 First Street SW, Rochester, Minnesota 55905. email: vangompel.jamie@mayo.edu. 